\title{
FAKTOR - FAKTOR YANG BERHUBUNGAN DENGAN \\ KEJADIAN HYPEREMESIS GRAVIDARUM PADA IBU HAMIL TRIMESTER I
}

\author{
Yosepina Otma Butu \\ Julia Rottie \\ Yolanda Bataha \\ Program Studi Ilmu Keperawatan Fakultas Kedoteran \\ Universitas Sam Ratulangi Manado \\ Email:ButuYosepinaa@gmail.com
}

\begin{abstract}
Hyperemesis gravidarum is a condition of excessive nausea and vomiting during pregnancy. Thepurpose of this study is to knowsomefactor that associated with the incidence of Hyperemesis Gravidarum in first trimester pregnant women atPuskesmasBahu Manado, and in this study, three factors were taken,There are age, parity status, and employment. Themethod of this study uses a quantitative method with a cross sectional design. The sample of this study was amounted to 30 people using total sampling method. The Resultsof this study, using the chi-square test, obtained the value of Asymp. Sig on the age variable is 0.964; on the parity variable 0.092; and the employment variable is 0.374. These results indicate that this value is $>0.05$, which means there is significant relationship between age, parity and employment with the incidence of hyperemesis gravidarum. Conclusion from the research conducted based on the relationship of factor related to the incidence of hyperemesis gravidarum, general,parity, and work there is a meaningful relationship.
\end{abstract}

Keywords: Hyperemesis Gravidarum

Abstrak: Hyperemesis gravidarum adalah keadaan mual dan muntah berlebihan selama masa kehamilan. Tujuan studi untuk melihat faktor-faktor yang berhubungan dengan kejadian Hyperemesis Gravidarum pada ibu hamil trimester I di Puskesmas Bahu Manado, dan dalam penelitian ini, diambil 3 faktor, yaitu umur, status paritas, dan pekerjaan ibu. Metode studi ini menggunakan metode kuantitatif dengan desain cross sectional. Sampel studi ini berjumlah 30 orang dengan menggunakan metode pengambilan sampel total sampling. Hasil dari penelitian ini, dengan menggunakan uji chi-square didapatkan bahwa nilai Asymp.Sig pada variabel umur adalah 0,964; pada variabel paritas 0,092; dan pada variabel pekerjaan sebesar 0,374 . Hasil ini menunjukkan bahwa Nilai ini > 0,05, yang berarti ada hubungan yang bermakna antara umur, paritas dan pekerjaan dengan kejadian hyperemesis gravidarum. Simpulan dari penelitian yang dilakukan berdasarkan hubungan faktor-faktor yang berhubungan dengan kejadian hyperemesis garavidarum,Umur Paritas dan Pekerjaan adalah ada hubungan yang bermakna.

Kata kunci :Hyperemesis Gravidarum

\section{PENDAHULUAN}

Menurut Nugraha (2007) World

Health Organization (WHO), jumlah kejadian Hyperemesis Gravidarum mencapai $12,5 \%$ dari seluruh jumlah kehamilan di dunia. Wanita di Indonesia yang mengalami kehamilan berjumlah 5.212.568 ibu hamil, dari jumlah ibu hamil yang mengalami Hyperemesis gravidarum mencapai 14,8\% Depkes RI (2013). Kehamilan Berisiko terhadap kesehatan ibu maupun janin di Sulawesi Utara, meliputi Perdarahan sebesar 17,22\%, hipertensi 23,95\%, infeksi 4,04\%, Hyperemesis gravidarum $27,65 \%$, ketuban pecah dini $17,07 \%$, 
kehamilan lewat waktu (Dinkes SULUT, 2013). Berdasarkan hasil pencatatan data dari Dinkes Propinsi Sulawesi Utara pada tahun 2017 terdapat ibu hamil, dengan hyperemesis gravidarum sebanyak 130 ibu hamil dari Puskesmas Bahu Manado yang telah ditinjau tahun 2017, wilayah Puskesmas Bahu Manado jumlah ibu hamil dengan keluhan hyperemesis gravidarum sebanyak 130 ibu hamil sedangkan Manado ibu hamil dengan hyperemesis gravidarum sebanyak 1000 ibu hamil (Propinsi Sulawesi Utara, 2015).

Mual dan muntah merupakan salah satu gejala paling awal, paling umum yang menyebabkan stress dan dikaitkan dengan kehamilan. Selama masa kehamilan sebanyak $90 \%$ wanita mengalami beberapa bentuk mual dan muntah yang dapat berkisar dari gejala mual ringan yang khas sampai sedang yang dapat sembuh dengan sendirinya atau tanpa disertai muntah, sampai kondisi berat, yaitu hyperemesis gravidarum. Sekitar 51,4\% wanita mengalami mual dan 9,2\% wanita mengalami muntah. Keadaan hiperemesis gravidarum yang sangat patologis jauh lebih jarang terjadi dibandingkan mual dan muntah secara logis, diperkirakan hiperemesis gravidarum yang sangat patologis terjadi dalam 1 per 500 kehamilan (Denise, 2008).

Hyperemesis Gravidarum merupakan mata rantai panjang yang dikendalikan oleh keseimbangan antara dopamin, serotonin, histamin dan asetilkolin. Menurunnya serotonin dalam darah dapat meningkatkan terjadinya mual dan muntah. Kejadian hyperemesis gravidarum berlangsung sejak usia kehamilan 9-10 minggu. Kejadian ini makin berkurang dan selanjutnya diharapkan berakhir pada usia kehamilan 12-14 minggu. Sebagian kecil berlanjut sampai usia kehamilan 20-24 minggu (Manuaba, 2008).

Keluhan mual muntah pada hyperemesis gravidarum merupakan hal yang fisiologis, akan tetapi apabila keluhan ini tidak segera diatasi maka akan menjadi hal yang patologis. Pada ibu yang mengalami keluhan mual dan muntah satu di antara seribu kehamilan gejala-gejala ini menjadi lebih berat. Hal ini disebabkan oleh meningkatnya kadar hormon estrogen dan HCG (Human Corionic Gonadotropin) dalam serum, selain itu progesterone juga diduga menjadi faktor penyebab mual dan muntah (Winkjosastro, 2007; Wesson, 2002). Hasil penelitian dari Stoppard (2007) menemukan bahwa wanita dengan usia yang lebih tua semakin cenderung mengalami keluhan mual muntah, sedangkan penelitian dari Yunia Mariati (2012) menemukan wanita-wanita muda lebih cenderung mengalami morning sickness. Faktor psikologis yang mempengaruhi terjadinya emesis gravidarum juga terdiri dari stress, dukungan suami dan keluarga serta faktor lingkungan sosial, budaya dan ekonomi (Prawirohardjo, 2010). Penelitian ini bertujuan untuk diketahui faktor-faktor yang berhubungan dengan kejadian hyperemesis gravidarum pada Ibu hamil di Puskesmas Bahu Manado

\section{METODE PENELITIAN}

Desain penelitian yang digunakan adalah desain penelitian Kuantitatif, dengan pendekatan Cross Sectional. Penelitian dilaksanakan di Pukesmas Bahu Manado pada bulan November 2018 - Juni 20119. Populasi dalam penelitian ini adalah semua Ibu hamil yang melakukan kunjungan di Puskesmas bahu manado pada bulan November- Juni tahun 2019 yaitu sebanyak 130 Ibu hamil. Semakin besar sample dari besarnya populasi yang ada adalah semakin baik, akan tetapi ada jumlah batas minimal yang harus diambil oleh peneliti yaitu sebanyak 30 sampel,sebagai mana dikemukakan oleh Baley dalam Mahmut (2001) yang menyatakan bahwa untuk penelitian yang menggunakan analisis data statistik, ukuran sampel minimum 
adalah 30.Instrumen dalam penelitian ini adalah lembar observasi, dengan kriteria penilaian yaitu nama (Inisial), umur, usia kehamilan, paritas, pekerjaan, dan adanya kejadian hyperemesis gravidarum.

Analisis univariat dimaksudkan untuk mengetahui distribusi frekuensi dengan proporsi variabel - variabel yang diamati baik variabel independen maupun variabel dependen. Analisa bivariat bertujuan untuk melihat hubungan variabel independen dan variabel dependen untuk membuktikan adanya hubungan dua variabel independen, uji yang dipakai chi-square dengan batas kemaknaan. Untuk menentukan uji kemaknaan hubungan dengan cara membandingkan nilai (value) dengan nilai $\alpha=0,05$ pada taraf kepercayaan $95 \%$.

\section{HASIL dan PEMBAHASAN}

Tabel 1. Deskripsi Karakteristik Responden Berdasarkan Umur

\begin{tabular}{ccc}
\hline Umur & $\mathrm{n}$ & $\%$ \\
\hline <20Tahun & 1 & 3,3 \\
20-35 Tahun & 28 & 93,3 \\
$>$ 35 Tahun & 1 & 3,3 \\
\hline Total & 30 & 100 \\
\hline
\end{tabular}

Sumber: Data Primer 2019

Tabel 2. Deskripsi Karakteristik Responden Berdasarkan Paritas

\begin{tabular}{ccc}
\hline Paritas & $\mathrm{n}$ & $\%$ \\
\hline Primipara & 22 & 73,3 \\
Multipara & 8 & 26,7 \\
\hline Total & 30 & 100
\end{tabular}

Sumber: Data Primer 2019

Tabel 3. Deskripsi Karakteristik Responden Berdasarkan Pekerjaan

\begin{tabular}{ccc}
\hline Pekerjaan & $\mathrm{n}$ & $\%$ \\
\hline Bekerja & 13 & 43,3 \\
\hline TidakBekerja & 17 & 56,7 \\
\hline Total & 30 & 100 \\
\hline Sumber: Data Primer 2019 & &
\end{tabular}

Tabel 4. Deskripsi Karakteristik Responden Berdasarkan Hyperemesis Gravidarum

\begin{tabular}{cccc}
\hline Hyperemesis Gravidarum & $\mathrm{n}$ & $\%$ \\
\hline & Berat & 0 & 0 \\
& Sedang & 1 & 3.3 \\
& Ringan & 29 & 96,7 \\
\hline Total & & 30 & 100 \\
\hline
\end{tabular}

Sumber: Data Primer 2019

Tabel 5. Hubungan Antara Umur, Paritas, dan Pekerjaan dengan Hyperemesis Gravidarum pada ibu hamil trimester $1 \mathrm{Di}$ Puskesmas Bahu Manado

\begin{tabular}{|c|c|c|c|}
\hline Variabel & Value & Df & $p$-value \\
\hline Umur & 0,74 & 2 & 0,964 \\
\hline Paritas & 2,845 & 1 & 0,092 \\
\hline Pekerjaan & 0,791 & 1 & 0,374 \\
\hline Total & 30 & 1 & 100 \\
\hline
\end{tabular}

Tabel 6. Hubungan Antara Umur dengan Hyperemesis Gravidarum pada ibu hamil trimester 1 di Puskesmas Bahu Manado.

\begin{tabular}{|c|c|c|c|c|c|c|c|}
\hline \multirow{3}{*}{ Umur } & \multicolumn{6}{|c|}{ Hyperemesis Gravidarum } & \multirow{3}{*}{$\begin{array}{c}p \\
\text { value }\end{array}$} \\
\hline & \multicolumn{2}{|c|}{ Ringan } & \multicolumn{2}{|c|}{ Berat } & \multicolumn{2}{|c|}{ Total } & \\
\hline & $\mathbf{n}$ & $\%$ & $\mathbf{n}$ & $\%$ & $\mathbf{n}$ & $\%$ & \\
\hline$<25$ Tahun & 18 & 81,8 & 4 & 18,2 & 22 & 100 & \\
\hline $\begin{array}{l}\geq 25 \\
\text { Tahun }\end{array}$ & 3 & 37,5 & 5 & 62,5 & 8 & 100 & 0,032 \\
\hline Total & 21 & 70,0 & 9 & 30,0 & 30 & 100 & \\
\hline
\end{tabular}

Tabel 7. Hubungan Antara Paritas dengan Hyperemesis Gravidarum pada ibu hamil trimester 1 di Puskesmas Bahu Manado

\begin{tabular}{|c|c|c|c|c|c|c|c|}
\hline \multirow{3}{*}{ Paritas } & \multicolumn{6}{|c|}{ Hyperemesis Gravidarum } & \multirow{3}{*}{$\begin{array}{c}p \\
\text { value }\end{array}$} \\
\hline & \multicolumn{2}{|c|}{ Primipara } & \multicolumn{2}{|c|}{ Multipara } & \multicolumn{2}{|c|}{ Total } & \\
\hline & $\mathbf{n}$ & $\%$ & $\mathbf{n}$ & $\%$ & $\mathbf{n}$ & $\%$ & \\
\hline Primipara & 17 & 77,3 & 5 & 22,7 & 22 & 100 & \\
\hline Multipara & 4 & 50,0 & 4 & 50,0 & 8 & 100 & 0,195 \\
\hline Total & 21 & 70,0 & 9 & 30,0 & 30 & 100 & \\
\hline
\end{tabular}

Tabel 8. Hubungan Antara Paritas dengan Hyperemesis Gravidarum pada ibu hamil trimester 1 di Puskesmas Bahu Manado 


\begin{tabular}{|c|c|c|c|c|c|c|c|}
\hline \multirow{3}{*}{ Paritas } & \multicolumn{6}{|c|}{ Hyperemesis Gravidarum } & \multirow{3}{*}{$\begin{array}{c}p \\
\text { value }\end{array}$} \\
\hline & \multicolumn{2}{|c|}{ Primipara } & \multicolumn{2}{|c|}{ Multipara } & \multicolumn{2}{|c|}{ Total } & \\
\hline & $\mathbf{n}$ & $\%$ & $\mathbf{n}$ & $\%$ & $\mathbf{n}$ & $\%$ & \\
\hline Primipara & 17 & 77,3 & 5 & 22,7 & 22 & 100 & \\
\hline Multipara & 4 & 50,0 & 4 & 50,0 & 8 & 100 & 0,195 \\
\hline Total & 21 & 70,0 & 9 & 30,0 & 30 & 100 & \\
\hline
\end{tabular}

Tabel 9. Hubungan Antara Pekerjaan dengan Hyperemesis Gravidarum pada ibu hamil trimester 1 di Puskesmas Bahu Manado

\begin{tabular}{|c|c|c|c|c|c|c|c|}
\hline \multirow{3}{*}{ Pekerjaan } & \multicolumn{6}{|c|}{ Hyperemesis Gravidarum } & \multirow{3}{*}{$\begin{array}{c}p \\
\text { value }\end{array}$} \\
\hline & \multicolumn{2}{|c|}{ Berat } & \multicolumn{2}{|c|}{ Ringan } & \multicolumn{2}{|c|}{ Total } & \\
\hline & $\mathbf{n}$ & $\%$ & $\mathbf{n}$ & $\%$ & $\mathbf{n}$ & $\%$ & \\
\hline Bekerja & 5 & 41,7 & 7 & 58,3 & 12 & 100 & \\
\hline Tidak Bekerja & 16 & 88,9 & 2 & 11,0 & 18 & 100 & 0,013 \\
\hline Total & 21 & 70,0 & 9 & 30,0 & 30 & 100 & \\
\hline
\end{tabular}

Sumber: Data Primer, 2019

Hasil uji chi - square dengan menggunakan aplikasi SPSS 21.0, didapatkan nilai Asymp.Sig pada variabel Umur adalah 0,032 dimana nilai ini> 0,05 , dari hasil uji tersebut maka disimpulkan H0 tidak terima, artinya ada hubungan bermakna antara Umur ibu hamil di trimester 1 dengan kejadian hyperemesis gravidarum. Selanjutnya untuk variabel Paritas, didapatkan nilai Asymp.Sig $>0,05$ yaitu 0,161 sehingga dapat disimpulkan H0 tidak diterima, artinya ada hubungan bermakna antara paritas dengan kejadian hyperemesis gravidarum pada ibu hamil trimester 1 di puskesmas bahu Manado. Dan pada variabel pekerjaan, didapatkan nilai Asymp.Sig 0,374 (> 0,009) dimana H0 tidak diterima, atau dapat disimpulkan bahwa pekerjaan ibu hamil trimester 1 ada berhubungan dengan kejadian hyperemesis gravidarum.

Penelitian yang dilakukan menunjukkan pada hubungan antara ketiga variabel yaitu Umur, Paritas dan Pekerjaan dengan kejadian Hyperemesis
Gravidarum. Hal ini sejalan dengan penelitian yang dilakukan oleh Aril Cikal YasaAr (2012), yang menyatakan bahwa ada terdapat hubungan yang bermakna antara usia ibu dan jumlah gravida dengan kejadian hyperemesis gravidarum, faktor yang punya hubungan bermakna dengan kejadian hiperemesis gravidarum adalah usia gestasi ibu.

Pujiati (2009) melakukan penelitian terhadap faktor-faktor yang dapat mempengaruhi terjadinya kejadian hyperemesis gravidarum pada trimester pertama Ibu hamil, dan didapatkan hasil bahwa paritas juga mempengaruhi kejadian hyperemesis gravidarum,faktor lain yang dapat mempengaruhi kejadian hyperemesis gravidarum adalah jenis makanan, psikologi ibu, riwayat hyperemesis gravidarum pada kehamilan sebelumnya, juga kebiasaan bangun tidur yang tergesa-gesa dan tidak langsung bangun, dapat mempengaruhi kejadian hyperemesis gravidarum.

M.Igbal (2016) melakukan penelitian terhadap faktor-faktor yang dapat mempengaruhi terjadinya hyperemesis gravidarum pada trimester pertama Ibu hamil, dan didapatkan hasil bahwa paritas juga tidak mempengaruhi kejadian hyperemesis gravidarum, faktor lain yang dapat mempengruhi kejadian hyperemesis grvidarum adalah tingkat pendidikan dan sosial ekonomi, dan terdapat hubungan yang bermakna antara usia ibu hamil dengan kejadian hyperemesis gravidarum. Peneliti berasumsi bahwa faktor usia ibu, paritas dan pekerjaan, bukan merupakan faktor utama terjadinya Hyperemesis Gravidarum sehingga didapatkan pada hasil penelitian, faktor-faktor tersebut mempengaruhi tentang Hyperemesis Gravidarum hal ini disebabkan, masih banyak factor lain yang dapat mempengaruhi kejadian Hyperemesis Gravidarum.

Keterbatasan peneliti sampel hanya ada pada kategori Hyperemesis Gravidarum sedang-ringan dan usia pada dua kategori 
yaitu $<20$ tahun dan 20-35 tahun jumlah sampelnya $30 \mathrm{ibu}$ hamil, belum dapat meneliti keseluruh populasi ibu hamil.

\section{SIMPULAN}

Penelitian yang dilakukan berdasarkan faktor-faktor yang berhubungan dengan kejadian hyperemesis Gravidarum umur, paritas dan pekerjaan dengan kejadian hyperemesis gravidarum kemudian Ada hubungan yang bermakna antara umur, paritas dan Pekerjaan ibu hamil dengan kejadian hyperemesis gravidarum.

\section{DAFTAR PUSTAKA}

Denise, T. 2008. Mual dan Muntah Kehamilan. Jakarta ; EGC.

Depkes RI, 2013.Tentang mual dan muntah

Dinas Kesehatan Provinsi Sulawesi Utara. 2004.Tentang ibu hamil

Dinas Kesehatan Propinsi Sulawesi Utara. 2017.Tentang maternitas

M.iqbal, 2016 Faktor - Faktor yang berhubungan dengan kejadian hyperemesis gravidarum di Rumah Sakit Umum Daerah Palembang

Manuaba. 2008. Buku Ajar ; Patologi Obstetri - Untuk Mahasiswa Kebidanan.Jakarta: EGC.

Mahmut, 2001. Kehamilan dan PersalinanJakarta: EGC

Nugraha, 2007. Menurut World Health Organization $\mathrm{WHO}$

Pujiati, 2009. Hubungan Umur Ibu dengan

HiperemesisGravidarum.

Kejadian

http:www.kti-kompre.blogspot.com, diakses tanggal 5 Januari 2011

Prawirohardjo, S. 2010. Ilmu Kebidanan.Edisi IV. Jakarta ; PT. Bina Pustaka
Stoppard. 2007. Hiperemesis Gravidarum.Edisi 4. Jakarta: EGC.

Winkjosastro, 2007. Faktor-Faktor penyebab mual dan muntahEdisi 4 . Jakarta ; EGC

Wesson, 2002. Faktor-Faktor penyebab mual dan muntahEdisi 4. Jakarta ; EGC

Yunia M. 2011. Kehamilan pada Ibu hamil.Jakarta ; EGC.

Yasa C, 2009 Faktor - Faktor yang berhubungan dengan kejadian Hyperemesis gravidarum pada ibu hamil trimester pertama di Puskesmas Ngampilan Yokyakarta. 